\title{
CD4 antibody treatment in patients with active Crohn's disease: a phase 1 dose finding study
}

A Stronkhorst, S Radema, S-L Yong, H Bijl, I J M ten Berge, G N J Tytgat, S J H van Deventer

\begin{abstract}
Background-T cells play an important part in Crohn's disease. Immunomodulating therapies that target $T$ cell activation may have clinical effects in Crohn's disease.

Aim-To investigate the toxicity and potential efficacy of anti-CD4 monoclonal antibody therapy in patients with Crohn's disease.
\end{abstract}

Patients and methods-A dose escalating pilot study was conducted in three groups of four patients with intractable Crohn's disease, refractory to steroids. They received 70,210 , or $700 \mathrm{mg}$ of $\mathrm{cM}-\mathrm{T} 412$, a depleting anti-CD4 monoclonal antibody (mAb).

Results-The mean reduction in Crohn's disease activity index (CDAI) was respectively $25 \%, 24 \%$, and $36 \%$ at four weeks, and $24 \%$ and $52 \%$ at 10 weeks in the $210 \mathrm{mg}$ and $700 \mathrm{mg}$ groups. There was only a minor effect on endoscopically evaluated disease activity. Side effects were mild to moderate fever with chills and headache. No signs of opportunistic infection were seen. There was a sustained decrease in CD4 count which lasted at least four weeks in the $70 \mathrm{mg}$ group (76.3 (SD $40 \cdot 6$ ) $\%$ of the baseline value) and 10 weeks in both the $210 \mathrm{mg}$ group $(80.8$ (SD 60.9)\%) and the $700 \mathrm{mg}$ group $(24.8$ (SD 15.4)\%). The primary and secondary humoral immune response was not influenced by anti-CD4 mAb treatment.

Conclusion-This study shows the moderate potential efficacy of treatment of patients with Crohn's disease using a depleting chimeric monoclonal anti-CD4 antibody.

(Gut 1997; 40: 320-327)

Keywords: Crohn's disease, $\mathrm{T}$ cells, monoclonal antibody treatment, inflammatory bowel disease.

The treatment of steroid resistant Crohn's disease remains a clinical challenge. Surgery is usually non-curative and immunosuppressive treatment may be associated with substantial toxicity. Immunomodulating therapies that target $\mathbf{T}$ cell activation may have a clinical effect in severe Crohn's disease. Cyclosporin inhibits $T$ cell activation by interfering with the transcription of interleukin-2 (II-2), which is an early event in activation of CD4 as well as CD8 positive cells. ${ }^{1}$ Treatment of patients with active Crohn's disease with oral cyclosporin resulted in a decrease of disease activity. ${ }^{2} \stackrel{\frac{\pi}{D}}{\circ}$ However, the long term efficacy of cyclosporin in Crohn's disease is disappointing and is $\vec{\circ}$ associated with substantial toxicity. ${ }^{3}$ An alternative option for treatment of steroid $\vec{\omega}$ resistant Crohn's disease might be depletion of certain $\mathrm{T}$ lymphocyte subpopulations. Although the specific pathogenic $T$ lympho- $f$ cyte subpopulations in inflammatory bowel $\omega$ disease have not been characterised, most $\mathrm{T} N$ lymphocytes in the lamina propria express $\mathrm{CD}^{4}$ and lamina propria $\mathrm{CD} 4+$ cells of patients with Crohn's disease coexpress the $\vec{z}$ activation marker CD25. ${ }^{5}$ It has been reported that refractory Crohn's disease may improve in $\frac{5}{5}$ the course of the development of AIDS, which $\vec{\theta}$ is characterised by severe depletion of CD $4 \underset{v}{*}$ positive lymphocytes. ${ }^{6}$

Administration of monoclonal antibodies (mAbs) that recognise CD4+ lymphocytes has been reported to have beneficial effects in various animal models of autoimmune $\frac{D}{D}$ disease. ${ }^{78}$ The efficacy of anti-CD4 $\mathrm{mAbs}$ is in part related to interference in the interaction $\frac{0}{3}$ between the CD4 molecule and the constant regions of HLA class II molecules, thereby응 preventing effective antigen presentation. ${ }^{9}$ In addition, some of these mAbs are depleting, causing an important and prolonged decrease $\frac{\sigma}{3}$ in circulating CD4 lymphocyte counts. Finally, by as yet incompletely characterised mech- $\frac{\circ}{3}$ anisms, treatment with anti-CD4 mAb may result in the development of immunological tolerance.

To investigate the toxicity and potential efficacy of anti-CD4 mAb therapy in patients $\widetilde{N}$ with intractable, steroid refractory Crohn's N disease, we have conducted an open label, dose escalating study using cM-T412 (Centocor, Malvern, PA, USA), a human-mouse chimeric, depleting, anti-CD4 mAb. Here, we report on toxicity, possible efficacy, and specific $\stackrel{\oplus}{+}$ immunomodulating effects of this treatment.

\section{Methods}

\section{Patients}

In this open, phase one, dose finding study we을 enrolled three groups of four patients with active (Crohn's disease activity index (CDAI) ${ }^{10} \stackrel{0}{?}$ >150), longstanding, intractable Crohn's disease. The Table presents the characteristics of the patients. Patient 1 had an adapted CDAI, because he had a colonostomy with constant stool production. The diagnosis of Crohn's disease was made on generally accepted clinical, endoscopical, radiological, 
Clinical data for the patients with Crohn's disease treated with cM-T412 and the effect of this treatment on endoscopically evaluated disease activity

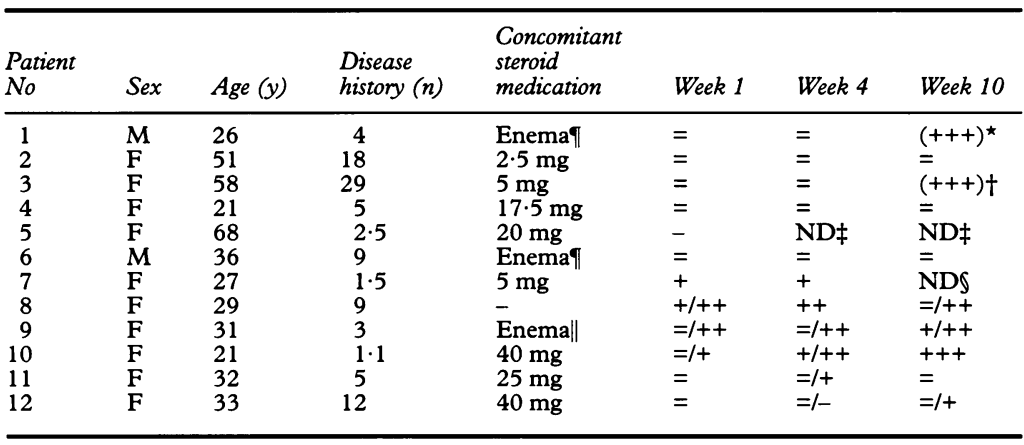

Patients 1 and 4 were treated for seven consecutive days with $10 \mathrm{mg} \mathrm{cM}-\mathrm{T} 412 \mathrm{mAb}$ daily $(70 \mathrm{mg}$ group). Patients $5,8,9$, and 12 were treated with respectively $30 \mathrm{mg}$ ( $210 \mathrm{mg}$ group) and $100 \mathrm{mg}(700 \mathrm{mg}$ group) daily. All patients but number 7 were concomitantly using oral mesalazine. Changes in endoscopy $v$ baseline are: $=$ no change, + minor improvement, ++ moderate improvement, +++ good improvement, ++++ disappearance of inflammatory signs, - minor worsening, -- moderate worsening, --- pronounced worsening. (ND=not done). ^Reported by referring physician; tstarted treatment with imuran/prednisolone at four weeks (end of protocol); †patient with colon perforation, colonostomy; ino endoscopy because of recent surgical correction of her colonostomy; ๆenemas containing $20 \mathrm{mg}$ prednisolone; \|enemas containing $2 \mathrm{mg}$ beclomethasone. and histological findings. Eleven patients had been shown to be unresponsive to treatment with at least $20 \mathrm{mg}$ corticosteroids and additional aminosalicylic acid derivatives for at least two weeks. One patient had previously experienced steroid induced diabetes mellitus. Excluded from the study were patients who had undergone previous administration of murine mAb, who had a history of alcohol or drug misuse, who had serum antibodies to $\mathrm{HIV}$, or who were unable to give informed consent in accordance with institutional guidelines. We also excluded patients on azathioprine or cyclosporin treatment, unless they had discontinued therapy for at least three months. In addition, inclusion required adequate renal (creatinine $<120 \mu \mathrm{mol} / \mathrm{l}$ ), hepatic (aspartate aminotransferase within twice the upper limit), and bone marrow function (haemoglobin $>6 \mathrm{mmol} / \mathrm{l}$, leucocytes $>3.5 \times 10^{9} / 1$, platelets $>100 \times 10^{9} / 1$ and CD4+ cells $\left.>0.5 \times 10^{9} / 1\right)$. Effective contraceptive methods were obligatory for those of reproductive age, until at least three months after treatment with $\mathrm{cM}-\mathrm{T} 412$. Women who were pregnant or lactating were excluded. Baseline clinical evaluations were performed after admission to the Academic Medical Centre in Amsterdam, within one week of screening for inclusion. The medication used before enrolment (prednisolone and mesalazine) was continued at a stable regimen throughout the study and follow up period. Written informed consent was obtained from all patients and the study was approved by the hospital ethics review board.

\section{Treatment}

cM-T412 mAb is a chimeric molecule that contains the $\mathrm{V}$ domains of the mouse anti-CD4 $\mathrm{Ab}$, grafted onto the human IgGl $\kappa$ constant domains. It recognises epitopes located in V1-2 domains of the CD4 molecule, and cross reacted with $\mathrm{T}$ lymphocytes from 50 donors. Three dosage groups of four patients each were treated for seven consecutive days with a two hour infusion of 10,30 , or $100 \mathrm{mg} \mathrm{cM-T412}$ $\mathrm{mAb}$. The corresponding groups therefore received a total dosage of 70,210 , or $700 \mathrm{mg}$ cM-T412 mAb. The dosage groups were selected on previous experience of patients with rheumatoid arthritis. Haemodynamic and respiratory variables were monitored during the infusions and the subsequent two hours. Each increase in dose was held back until safety assessment of the previous dose regimen.

\section{Follow up}

Laboratory variables were assessed immediately before and during the infusions. The assessment continued up to six hours after starting the infusion for the first five treatment days. Follow up examinations were performed on day 8, at four weeks, and at 10 weeks. Crohn's disease activity, side effects, and endoscopical and immunological variables were monitored. Because two referring physicians reported a beneficial effect in the $70 \mathrm{mg}$ group after 10 weeks, it was decided to extend the observation period from four weeks in the original protocol to 10 weeks in the $210 \mathrm{mg}$ and $700 \mathrm{mg}$ dosage groups.

\section{Endoscopical monitoring}

The effect of cM-T412 mAb on mucosal inflammation was endoscopically monitored and registered on videotape. Two independent experienced gastroenterologists judged the videotapes, using the endoscopical score described by Mary and Modigliani. ${ }^{11}$ They were blinded for the dosage group and date of the endoscopy. Follow up endoscopy was compared with baseline endoscopy and scored to show no change, minor improvement, moderate improvement, good improvement, disappearance of inflammatory signs, minor worsening, moderate worsening, and pronounced worsening.

\section{Laboratory testing}

Blood samples for routine complete blood cell count, platelet count, electrolytes, renal and liver chemistry, and analysis of urine were obtained at inclusion, preinfusion, and 1, 4, and 10 weeks after the first infusion. An HIV test and a pregnancy test were performed at inclusion.

\section{Immunophenotyping}

Immunophenotype analysis was performed by direct immunofluorescence with a panel of commercially available mAbs utilising a single laser FACScan flow cytometer (Becton Dickinson, Mountain View, CA, USA) as described before. ${ }^{12}$ The absolute number of cells of each subset was calculated by multiplication with the absolute lymphocyte count. The CD4 Ab used had previously been shown to recognise a different epitope than cM-T412. ${ }^{13}$ The following mAbs were used: CD2 (anti-Leu-5b, IgG2a), CD3 (anti-Leu-4, 
IgG1), CD4 (anti-Leu-3a, IgG1), CD8 (antiLeu-2a, IgG1), CD19 (anti-Leu-12, IgG1), CD25 (anti-IL-2 receptor, IgG1), all obtained from Becton Dickinson, Mountain View, CA, USA.

Humoral immune response in patients treated with $c M-T 412 m A b$

To test primary and secondary humoral immune responses in patients treated with $\mathrm{cM}$ T412 mAb, patients were immunised five minutes before initiation of the first cM-T412 $\mathrm{mAb}$ infusion with $1.0 \mathrm{mg}$ keyhole limpet haemocyanin (KLH) subcutaneously, and with $1 \mathrm{ml}$ tetanus toxoid intramuscularly in the quadriceps region. IgG anti-KLH Abs were measured with an enzyme linked immunosorbent assay (ELISA), as described previously. ${ }^{14}$ The KLH induced humoral immune response was expressed as the ratio between the IgG anti-KLH Ab concentration 14 days after and immediately before immunisation. IgG antitetanus Abs were measured by ELISA and the ratio of tetanus specific $A b$ concentrations was calculated. ${ }^{15}$ Twelve (11 women and one man) patients with Crohn's disease (mean CDAI 241, range 72-386), and 10 healthy subjects were also immunised and served as controls. The control patients with Crohn's disease were on comparable steroid dosage regimens and were not treated with immunosuppressive drugs.

\section{Soluble receptors and cytokines}

For cytokine detection, serum was collected by spinning clotted (one hour at room temperature) blood at $3000 \times g$ for 20 minutes. The serum was aliquoted in $1 \mathrm{ml}$ cups and stored at $-30^{\circ} \mathrm{C}$ until batchwise assay. The soluble IL-2 receptor concentration was determined with a commercial available sandwich type ELISA using two types of $\mathrm{mAb}$ recognising different epitopes of the IL-2 receptor (Eurogenetics, Tessenderlo, Belgium). Using this assay in normal controls $(n=323) 96 \%$ had concentrations less than 59 $\mathrm{U} / \mathrm{ml}$; the detection limit was $20 \mathrm{U} / \mathrm{ml}$. Serum tumour necrosis factor (TNF) concentrations were determined by immunoradiometric assay (Medgenix, Fleurus, Belgium) according to the manufacturer's instructions. This assay detects both free and soluble $\mathrm{TNF}$ receptor bound TNF. ${ }^{16}$ Soluble TNF receptors p55 and p75 were measured with enzyme linked immunological binding assays (ELIBAs, Hoffman-La Roche Ltd, Basel, Switzerland) as described previously using TNF binding non-inhibitory $\mathrm{mAb}$ against TNF receptors $\mathrm{p} 55$ or $\mathrm{p} 75 .{ }^{17}$ The intra-assay and the interassay variations were $3 \%-6 \%$ and $5 \%-10 \%$ respectively; the detection limit was $0 \cdot 1 \mathrm{ng} / \mathrm{ml}$. Concentrations of IL- 6 were determined with a commercial available ELISA, in which anti-huIL-6 Ab was coated to polystyrene microtitre wells (CLB, Amsterdam, The Netherlands). The detection limit in our laboratory was $1 \mathrm{pg} / \mathrm{ml}^{18}$ Concentrations of $\mathrm{sCD} 27$ were measured using CLB-CD27/1-3 mAb. Control subjects had concentrations between 100 and $200 \mathrm{U} / \mathrm{ml}$ and interassay and intra-assay coefficients of variation of the ELISA were below $10 \% .^{19}$

\section{Statistical analysis}

Clinical and immunological data are expressed as means (SD). The difference in lymphocyte (sub) counts and cytokine concentrations were $\stackrel{\vec{\rho}}{\rightarrow}$ analysed over time with repeated measures analysis of variance (ANOVA). Comparisons 흠 between groups were made by Mann-Whitney $\frac{\bar{c}}{7}$ $U$ and Wilcoxon rank tests. All reported sig- $\mathbb{Q}$ nificance levels are two tailed and $\alpha$ was set at $0 \cdot 05$.

\section{Results}

Clinical disease activity after infusion of cM-T412 $\overrightarrow{0}$ $m A b$

During the treatment week, the CDAI N decreased in nine of 12 patients. Compared with the baseline value, the CDAI had decreased in all but two patients by the fourth $\vec{z}$ week. The mean CDAI reduction at four weeks was $25 \%, 24 \%$, and $36 \%$ in the $70 \mathrm{mg}$, $\frac{\rho}{工}$ $210 \mathrm{mg}$, and $700 \mathrm{mg}$ groups respectively $\vec{\bullet}$ (Fig 1). The CDAI was prospectively calculated at later time points in the two highest dose groups only. At 10 weeks the CDAI had $\sum^{\circ}$ decreased in all eight patients with a mean of $\frac{\partial}{\partial}$ $24 \%$ and $52 \%$ respectively. The reduction of the CDAI in all patients treated with cM-T412 $\frac{}{\square}$ after one week was $9 \%(\mathrm{p}=0.049)$, at four $\overrightarrow{\vec{B}}$ weeks $26.4 \%(p=0.004)$, and at 10 weeks $39 \% \frac{O}{3}$ $(\mathrm{p}=0.012)$.

\section{Effect of treatment with $c M-T 412 m A b$ on the} endoscopical score

Endoscopy performed immediately after the infusion week and at the fourth week showed $\frac{0}{3}$ minor to moderate improvement in two o patients of both the 210 and $700 \mathrm{mg}$ groups

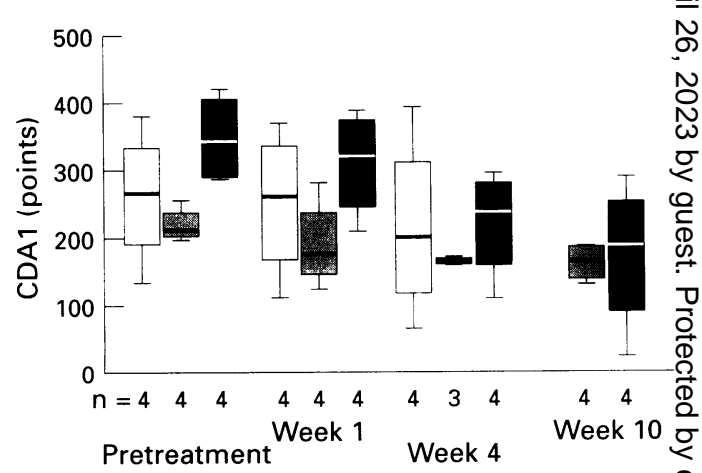

Figure 1: Effect of cM-T412 treatment on Crohn's disease activity index (CDAI) in the $70 \mathrm{mg}$ (open bar), $210 \mathrm{mg}$ (grey bar), and $700 \mathrm{mg}$ (black bar) groups. The graph represents the means (thick horizontal line) and 25th and 75 th percentiles (bar), and error bars indicate 5th and 95 th percentiles (thin line). The mean $C D A I$ in patients with Crohn's disease treated wtih cM-T412 decreased in all three treatment groups, at all time points compared with baseline. There were no significant differences within or between the groups. Ten out of 12 patients improved at four weeks and all eight patients improved at 10 weeks. All patients combind showed a significant decrease in $C D A I$ at one, four and 10 weeks with respectively $-9 \%(p<0.05),-26 \%$ $(p<0.005)$, and $-39 \%(p<0.01)$. 
(Table). Two patients in the $70 \mathrm{mg}$ group showed improvement of inflammatory lesions when assessed by their referring physician at 10 weeks. This was the reason for extending the study in the $210 \mathrm{mg}$ and $700 \mathrm{mg}$ groups up to 10 weeks. At 10 weeks one patient in the $210 \mathrm{mg}$ and two patients in the $700 \mathrm{mg}$ group showed improvement of the inflammatory lesions on colonoscopy. The endoscopical findings showed a poor relation with the CDAI. One patient (10) showed a major improvement in her inflammatory lesions. However, this did not result in an important decrease in her CDAI. Other patients (for example, patients 11 and 12) showed no endoscopical improvement, but the CDAI decreased dramatically.

Adverse experiences after treatment with antiCD4 mAb in patients with Crohn's disease

The infusion of cM-T412 mAb over a two hour period caused a mild to moderate increase in body temperature (range $37 \cdot 7-39 \cdot 7^{\circ} \mathrm{C}$ ) on the first infusion day in seven patients. In five patients this was accompanied by chills. Subsequent infusions caused no fever. Six patients in the 210 and $700 \mathrm{mg}$ groups had a mild to moderate headache. No respiratory, circulatory, or other clinical side effects were seen. Routine laboratory screening disclosed no effects on serum electrolytes, or renal or haematological variables (data not shown). One patient (11) had an unexplained temporary rise in serum transaminases (<twice the upper limit) at four weeks. One elderly patient (5) had a perforation of her sigmoid colon nine days after starting the first infusion. The perforation was located on the top of a diverticulum in a severely ulcerated bowel. The perforation was complicated by peritonitis requiring repeated laparotomies and long term intensive care. The reconvalescence period was further complicated by a pneumonia possibly caused by an actinomyces species (cultures remained negative). The CD4 counts were very low during the abdominal sepsis $\left(<0.01 \times 10^{9} / 1 \quad(<10 \%\right.$ from baseline $\left.)\right)$. The CD4 count recovered slowly during intensive care treatment, and eventually the patient recovered with a colostomy. In the other patients no signs of opportunistic infection were seen in the observation period and none have been reported to date.

\section{Changes in lymphocyte subpopulations}

Infusion of cM-T412 mAb was followed by a rapid (within one hour) decline in lymphocytes as assessed by Coulter counter (data not shown). This was caused mainly by a major decline in CD3+ and CD4+ lymphocytes and a minor and temporary decrease in CD8+ and CD19+ lymphocytes (data not shown). The CD4+ subpopulation (Fig 2) decreased dramatically within one hour in all three groups to a mean (SD) of $13.7(4 \cdot 9) \%, 24 \cdot 3(6 \cdot 1) \%$, and $23.5(10 \cdot 8) \%$ of the baseline value. Mean fluorescence intensity of CD4 expression showed a decrease (data not shown). Before the second infusion, the CD4+ lymphocyte

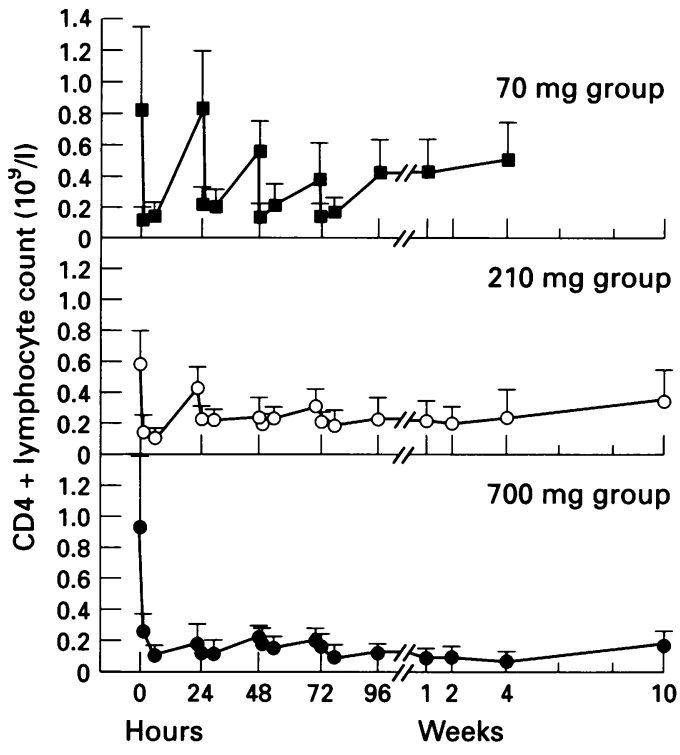

Figure 2: Response of peripheral blood CD4+ T cells to anti-CD4 mAb treatment. Mean (SD) peripheral CD4+ $T$-cell counts in three groups of four patients with Crohn's disease treated with a total dose of $70 \mathrm{mg}, 210 \mathrm{mg}$, or 700 mg cM-T412 mAb. CD4+ lymphocytes significantly ( $A N O V A p=0.049)$ decreased after the first mAb infusion. In the $70 \mathrm{mg}$ group CD4+ lymphocyte count returned to baseline before the next infusion, but repeated infusions led to a long term decrease. In the $210 \mathrm{mg}$ and $700 \mathrm{mg}$ groups the decreases in CD4+ lymphocyte counts were more substantial. Treatment with cM-T412 mAb seemed to result in a dose dependent lymphocyte reduction.

count had recovered to preinfusion values in the $70 \mathrm{mg}$ group. There was a partial recovery in the $210 \mathrm{mg}$ group. Repeated infusions led to a sustained decrease in both groups which lasted at least four weeks (maximum follow up period in this group) in the $70 \mathrm{mg}$ group (76.3 $(40.6) \%$ of the baseline value) and 10 weeks in the $210 \mathrm{mg}$ group $(80.8(60.9) \%$ of the baseline value). In the $700 \mathrm{mg}$ group no rebound effect was seen, and the number of CD4+ lymphocytes remained significantly decreased during follow up. At 10 weeks the CD4 count in the $700 \mathrm{mg}$ group was still significantly decreased to $24 \cdot 8(15 \cdot 4) \%$ of the baseline value. Hence, the reduction in the CD4 counts after cM-T412 showed a doseresponse relation that reached significance (ANOVA; $\mathrm{p}=0.049$ ). The CD8 count combined for all dose groups showed a 50\% decrease after the first $\mathrm{mAb}$ infusion. CD8 counts recovered before the second infusion, and only minor, non-significant changes occurred during the remainder of the study period. CD19+ lymphocytes showed a minor, non-significant decrease after the infusion of anti-CD4 mAb (data not shown).

\section{KLH and tetanus immunisations}

Patients with Crohn's disease treated with $\mathrm{cM}$ T412 mAb as well as Crohn's disease controls were found to have a significantly diminished primary humoral immune response. Healthy control subjects had a mean (SD) 13.7 (9.3)-fold increase in anti-KLH IgG concentration after immunisation, which was significantly higher $(p<0.001)$ than the 3.1 $(1 \cdot 6)$-fold increase in patients treated with $\mathrm{cM}$ - 


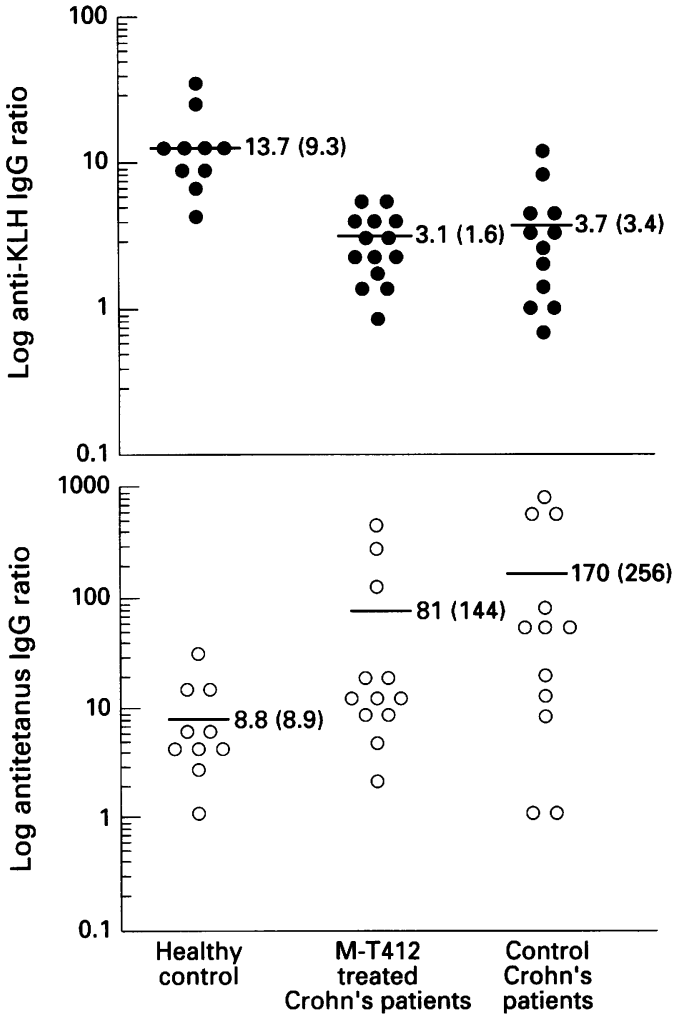

Figure 3: Primary and secondary immune response in Crohn's disease treated with cM-T412 mAb: to test primary keyhole limpet haemocyanin $(K L H)$ and secondary (tetanus) humoral immune response in patients treated with $c M-T 412 m A b$, patients were immunised with $K L H$, and tetanus toxoid five minutes before initiation of the first $c M-$ T412 mAb infusion. The responses are expressed as the ratio of the IgG antibody concentration 14 days after and immediately before immunisation. Twelve patients with Crohn's disease (mean CDAI 241.4, range 72-386) and 12 healthy subjects were used as controls. Patients with Crohn's disease showed significantly decreased primary immune response compared with controls. However, no differences were found between treated and non-treated patients with Crohn's disease. There was a normal to increased secondary immune response in patients with Crohn's disease, which was not influenced by cM-T412 treatment.

T412 and a 3.7 (3.4)-fold increase in patients with Crohn's disease. The secondary humoral immune responses were normal or increased when compared with healthy controls. An 8.8 (8.9)-fold increase in anti-tetanus IgG concentration was found in healthy controls compared with an 81 (144)-fold increase in cM-T412 mAb treated patients with Crohn's disease $(p<0.06)$ and a 170 (256)-fold increase in non-treated patients with Crohn's disease $(p<0.03)$. Patients treated with anti-CD4 did not differ in primary or secondary humoral immune response from non-treated patients with Crohn's disease (Fig 3).

Cytokine responses to infusion of cM-T412 $\mathrm{mAb}$ Infusion of cM-T412 caused TNF release as well as shedding of TNF receptors. Before infusion, TNF concentrations (mean (SD) $12.56(5.0) \mathrm{pg} / \mathrm{ml}$, range $1.9-19.9 \mathrm{pg} / \mathrm{ml})$ were slightly increased (normal value $<5.0 \mathrm{pg} / \mathrm{ml}$ ) and cM-T412 infusion caused a release of TNF in all patients to reach a peak concentration of $107 \cdot 27 \quad(46.06) \mathrm{pg} / \mathrm{ml}$ $(p<0.01$; (Fig 4)). The TNF concentrations

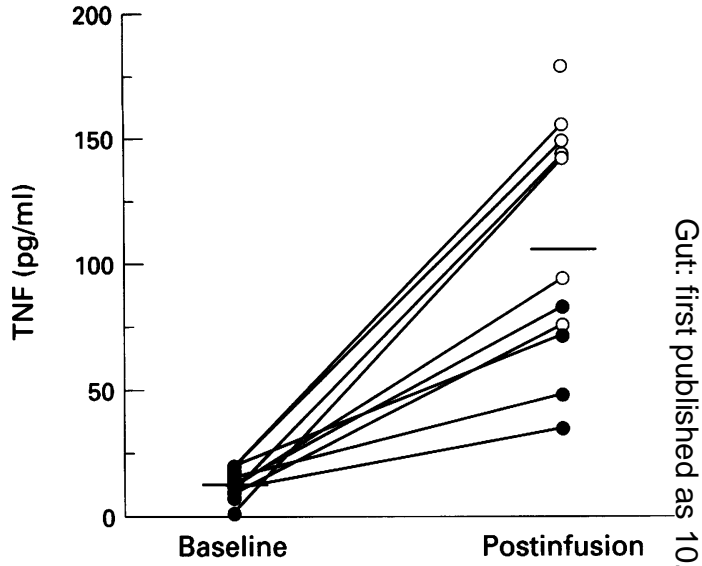

Figure 4: Response of serum TNF $\alpha$ to cM-T412 infusion. Individual baseline serum TNF $\alpha$ concentrations and the concentrations three hours after starting the first infusion period of $c M-T 412 \mathrm{mAb}$. No differences were found between the three dosage groups, but patients responding to the infusion with fever and chills (O) had higher postinfusion concentrations. Infusion of cM-T412 $\mathrm{mAb}$ resulted in a significant $(p<0.001)$ increase in the mean (SD) serum TNF concentration from $12 \cdot 7(5 \cdot 0) \mathrm{pg} / \mathrm{ml}$ to $107 \cdot 3$ (46.1) $\mathrm{pg} / \mathrm{ml}$ (horizontal black line).

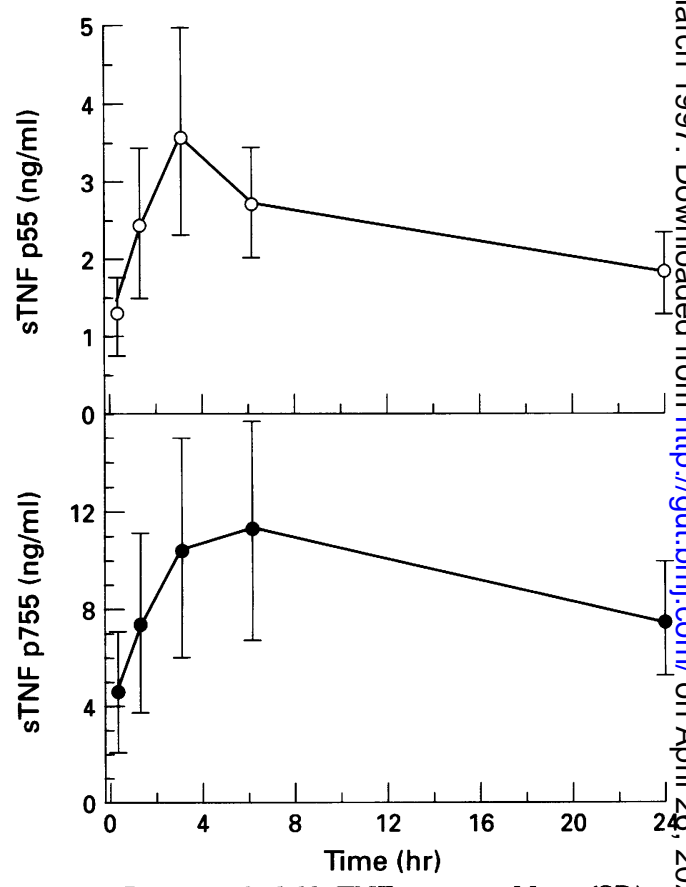

Figure 5: Response of soluble TNF receptors. Mean (SD) N soluble TNF receptor p55 and p75 concentrations in all patients treated with cM-T412 mAb combined showed a significant increase during the first infusion. The values remained increased during the infusion week, but returned to normal at week four. ( $p<0.001$ for $\mathrm{t}=1, \mathrm{t}=3, \mathrm{t}=6$, and $\mathrm{t}=24$ compared to baseline, and $p<0.05$ for $\mathrm{t}=168$ ).

increased most in those patients that developed $\frac{2}{\square}$ fever after the infusion (open circles in Fig 4). Soluble TNF receptors p55 and p75 showed a similar reaction to the antibody treatment, with normal pretreatment concentrations(mean 1.31 $(0.4) \mathrm{ng} / \mathrm{ml}$ and $4.57(2.47) \mathrm{ng} / \mathrm{ml}$ respectively) and maximum concentrations three hours after starting the infusion: mean $3.54(1.34) \mathrm{ng} / \mathrm{ml}$ and $12.34(4.94) \mathrm{ng} / \mathrm{ml}$ respectively). Concentrations of soluble TNF receptors remained increased during the $\mathrm{cM}$ T412 mAb infusion week and subsequently returned to baseline (Fig 5). Patient 5 had 
increased soluble TNF receptors during the complications that occurred in the follow up period (up to 10 weeks). The circulating IL-6 concentration rapidly increased after cM-T412 $\mathrm{mAb}$ infusion, reaching maximal concentrations three hours after initiation of the infusion (mean $17.99(31.11) \mathrm{pg} / \mathrm{ml} ; \mathrm{p}<0.01)$. In all patients except patient 5 the IL- 6 concentrations returned to baseline after the $\mathrm{cM}-\mathrm{T} 412$ $\mathrm{mAb}$ infusion period. Serum concentrations of both soluble IL-2 receptor and soluble CD27 showed no significant changes after the antiCD4 Ab treatment (data not shown).

\section{Discussion}

This study in patients with Crohn's disease refractory to steroids was designed to investigate the potential efficacy and safety of anti-CD4 $\mathrm{mAb}$ treatment and to determine an effective dosage scheme. Daily infusion of the chimeric (human/mouse) mAb cM-T412 during seven consecutive days at total doses of 70,210 , and $700 \mathrm{mg}$ resulted in a dose dependent reduction in the circulating CD4 count. After the initial infusion, the CD4+ lymphocyte counts recovered in both lower dosage groups, but finally remained depressed after the seven day course. Infusion of $100 \mathrm{mg}$ cM-T412 mAb daily immediately caused long term depression of the CD4 count. Despite the low CD4 counts, which in patients with HIV infection are considered a potential risk for opportunistic infections, none of these infections occurred in our patients, which is in line with the experience from other clinical studies using murine or chimeric anti-CD4 mAb. ${ }^{20-23}$ One patient infused with $\mathrm{cM}-\mathrm{T} 412$ had a complicated course (see results) which was complicated by bacterial sepsis. Despite very low CD4+ lymphocytes she was able to fight the abdominal sepsis, and intercurrent pneumonia, and repeated surgery. She eventually recovered.

Anti-CD4 mAb infusion may interfere with the measurement of circulating $\mathrm{CD} 4+$ cells using flow cytometry. This possibility was excluded, however, in this study. Firstly, the antibody used for CD4+ cell count assessment has been reported to recognise the CD4 molecule even after binding of cM-T412 $\mathrm{mAb} .{ }^{13}$ Furthermore, the decrease in $\mathrm{CD} 3$ counts matched the decrease in CD4 counts. This finding suggests that CD4 and CD3 positive cells are actually depleted from the circulating lymphocyte pool, and makes mere modulation or coating of the CD4 molecule less likely. However, the decrease in mean fluorescence intensity on the remaining CD4 positive cells indicates that modulation or coating occurred as well, as has been reported previously. ${ }^{24}$ The CD4 depletion after infusion of cM-T412 mAb in the present study is comparable with findings after cM-T412 mAb treatment of patients with refractory rheumatoid arthritis, ${ }^{13}$ in whom lower doses of cM-T412 mAb caused longer lasting CD4+ cell depletion. The apparent differences in sensitivity to cM-T412 mAb between patients with Crohn's disease and those with rheumatoid arthritis remain to be explained, but it should be noted that in the present study no concomitant immunosuppressive drugs were given. By contrast with our study population, many patients with rheumatoid arthritis treated with $\mathrm{cM}-\mathrm{T} 412 \mathrm{mAb}$ were treated with methotrexate. After the first infusions of cM-T412 mAb, there were transient changes in the CD8+ and CD19+ cell counts. However, after seven days of treatment these cell counts had returned to baseline, and both the CD8 and CD19 (B cell) counts remained unchanged at later time points. Infusion of cM-T412 mAb caused a mild cytokine release syndrome, of which at least $\mathrm{TNF} \alpha$ may have contributed to the initial decreases in CD8+ and CD19+ cell counts. ${ }^{25}$ Shortly after the first infusion, increases in IL$6, T N F$, and sTNF receptor concentrations were found, that seemed to cause the febrile reaction that occurred in seven of 12 patients. The cause of this immunostimulatory effect of anti-CD4 remains unknown. Possible explanations include complement activation induced by bound cM-T412, direct cross linking, and stimulation of $\mathrm{T}$ cells, Fc receptor mediated stimulation, or by removal of CD4 coated cells by phagocytic cells. Both complement activation and $\mathrm{Fc}$ receptor mediated stimulation are less likely in treatment with a chimeric mAb. Others ${ }^{13} 26$ also found transient increases in IL-6, but not in TNF concentrations. Possibly the time of sampling (three hours after the first infusion in our study versus two weeks in the study of Moreland et $a l^{13}$ ) and the determination method contribute to this difference. Although cM-T412 mAb caused release of TNF and IL-6, its toxicity seemed minor when compared with OKT3 infusion. Treatment with OKT3 is usually accompanied by high fever, chills, and multiple other side effects, which may be attributed to complement activation. ${ }^{27}$

A decrease in the CDAI at four weeks was noted in 10 out of 12 patients and at 10 weeks all eight evaluated patients improved. The mean CDAI decreased from baseline 265 to 216 (four weeks) in the $70 \mathrm{mg}$ group, from 221 to 166 (four weeks) and 163 (10 weeks) in the $210 \mathrm{mg}$ group, and from 348 to 221 and 174 in the $700 \mathrm{mg}$ group. These data should be interpreted cautiously, because of the open label design of the study, the small number of patients, and the well known occurrence of spontaneous remissions in patients with Crohn's disease. In only two of eight patients the CDAI decreased below 150, which is considered to indicate a complete remission. Hence, our results contrast with the previously reported beneficial effect of cM-T412 treatment on Crohn's disease. ${ }^{28}$ Treatment with cM-T412 had only a minor effect on the endoscopical appearance of the involved bowel, as scored by the Modigliani index using videotapes, and the endoscopical appearance did not correlate with the CDAI.

Although depletion of CD4+ cells did not cure Crohn's disease, this finding does not exclude an important role for CD4 positive cells in the pathogenesis of Crohn's disease. 
The infusion of the CD45RBhigh subset of CD4 positive cells from normal BALB/c mice causes inflammatory bowel disease in B-17 scid mice. A combined infusion of CD45RBhigh and CD45RBlow BALB/c CD4+ lymphocytes does not induce disease in scid mice, however, indicating the differential pathogenic importance of specific phenotypic subpopulations within the CD4 compartment. ${ }^{29}$ If these findings can be extrapolated to humans, they may explain why depletion of all CD4+ lymphocytes has only minor therapeutic effect in patients with active Crohn's disease.

Anti-CD4 mAbs inhibit primary and secondary antibody responses to antigens in animal experiments. ${ }^{30}{ }^{31}$ The effect of cMT412 mAb treatment on "B cell" response was investigated by vaccination with $\mathrm{KLH}$ and tetanus toxoid. The already diminished primary humoral immune response in patients with Crohn's disease compared with healthy controls seemed not to be affected. Both treated and control patients with Crohn's disease had diminished primary antibody responses to $\mathrm{KLH}$ when compared with normal controls. The secondary humoral immune reactivity in patients with Crohn's disease showed a scattered pattern and was significantly increased in the patient group compared with healthy controls. Treatment with $\mathrm{cM}-\mathrm{T} 412 \mathrm{mAb}$ seemed not to affect this response, indicating at least a normal memory cell function. These data suggest that antiCD4 $\mathrm{mAb}$ in the tested doses left both primary and secondary immune responses unimpaired, at least when immunisation was carried out in the early phase of treatment. However, it is conceivable that a diminished response might occur when patients are immunised after therapy has started. Our data also suggest that despite depleting CD4+ cells for $90 \%$ or more in some patients, the secondary immune response remains intact. Apparently the memory cells are resistant to depletion by $\mathrm{cM}$ T412 mAb. Patients can therefore fight previously encountered agents and recover, for instance, from sepsis. However, this means that in patients with Crohn's disease the immune response to such a previously encountered antigen in the bowel persists. To cure our patients we have to delete all memory cells that mediate the immune response in Crohn's disease. Therefore the responsible antigen(s) have to be known.

In conclusion, this pilot study demonstrates the feasibility of treatment of patients with Crohn's disease using a depletion chimeric monoclonal anti-CD4 antibody. Treatment resulted in a dose-dependent reduction in the CDAI and circulating CD4 count. Controlled studies with high dose cM-T412 mAb are necessary to evaluate further the efficacy of anti-CD4 treatment in Crohn's disease.

We thank Centocor, Malvern, PA, USA, for the supply of cMT412 mAb and Th A Out, Laboratory of Clinical Immunology of the Academic Medical Centre, Amsterdam, for determining the tetanus and KLH concentrations.

This work has appeared in abstract form as: Stronkhorst A, Yong SL, Radema SA, ten Berge I, Das PK, Tytgat GN, van monoclonal M-T 412 (Anti CD4) antibodies in Crohn's disease. Preliminary data. Gastroenterology 1992; 102: A702.
1 Schreiber SL, Crabtree CR. The mechanism of action of cyclosporin A and FK506. Immunol Today 1992; 13: 136-42.

2 Brynskov J, Freund L, Rasmussen SN, Lauritsen K Schaffalitzky de Muckadell O, Williams N, et al. A placebo-controlled, double-blind, randomized trial of cyclosporine therapy in active chronic Crohn's disease. $N$ Engl f Med 1989; 321: 845-50.

3 Feagan BG, McDonald JWD, Rochon J, Laupagis A, Fedorak RN, Kinnear D, et al. Low-dose cyclosporin for the treatment of Crohn's disease. N Engl F Med 1994; 330: $1846-51$.

4 Konoff ME, Strober W, Fiochi C, Zeitz M, James SP. CD4 positive Leu-8 negative helper-inducer T-cells $\overrightarrow{\bar{N}}$ predominate in the human intestinal lamina propria. $f \stackrel{f}{\rightarrow}$ predominate in the human
Immunol 1988; 14: 3029-36.

5 Choy MY, Walker-Smith JA, Williams CB, MacDonald TT. Differential expression of CD25 (interleukin-2 receptor) $\overline{\bar{c}}$ on lamina propria $T$ cells and macrophages in the $\frac{S}{T}$ intestinal lesions in Crohn's disease and ulcerative colitis. Gut 1990; 31: 1365-70.

6 James SP. Remission of Crohn's disease after human immunodeficiency virus infection. Gastroenterology 1988; $\rightarrow$ 95: 1667-69.

7 Wofsy D, Seaman WE. Reversal of advanced murine lupus in NZB/NZW F1 mice by treatment with monoclonal $\vec{G}$ antibody to L3T4. F Immunol 1987; 138: 3247-53.

8 Christadoss P, Dauphinee MJ. Immunotherapy for myasthenia gravis: a murine model. F Immunol 1986; 136: $2437-40$.

9 Julius M, Maroun CR, Haughn L. Distinct roles for CD4 $\overrightarrow{0}$ and CD8 as co-receptors in antigen receptor signaling. $\omega$ Immunol Today 1993; 14: 177-87.

10 Best WR, Becktel JM, Singleton JW, Kern F. Development N of a Crohn's disease activity index. Gastroenterology 1976; 70: $439-44$.

11 Mary JY, Modigliani R, GETAID. Development and validation of an endoscopic index of the severity for $\overrightarrow{ }$ Crohn's disease: a prospective multicentre study. Gut 1989; 30: 983-9.

12 Parlevliet KJ, ten Berge IJM, Yong SL, Surachno J, Wilmink $\frac{\widehat{\rho}}{\supset}$ $\mathrm{JM}$, Schellekens PTA. In vitro effects of IgA and IgG2a anti-CD3 isotype switch variants. $\mathcal{F}$ Clin Invest 1994; 93: 2519-25.

13 Moreland LW, Bucy RP, Tilden A, Pratt PW, Lobuglio AF, . Khazaeli M, et al. Use of a chimeric monoclonal anti-CD4 antibody in patients with refractory rheumatoid arthritis. Arthritis Rheum 1993; 36: 307-18.

14 van der Heyden AAPAM, Bloemena E, Out TA, Wilmink JM, Schellekens PThA, van Oers MHJ. The influence of immunosuppressive treatment on the immune responsiveness in vivo in kidney-transplant recipients. Transplantation 1989; 48: 44-7.

15 Devey ME, Bleasdale K, Lee S, Rath S. Determination of $\overrightarrow{\vec{O}}$ the functional affinity of IgG1 and IgG4 antibodies to 3 tetanus toxoid by isotype-specific solid-phase assays. $\mathcal{F}$ Immunol Methods 1988; 106: 119-25.

16 Engelberts I, Stephens S, Francot GJM, van der Linden CJ, Buurman WA. Evidence for different effects of soluble TNF-receptors on various TNF measurements in human TNF-receptors on various TNF measure
biological fluids. Lancet 1991; 338: 512 .

17 Godfried MH, van der Poll T, Jansen J, Romijn JA, Eeftinck Schattenkerk JKM, Endert E, et al. Soluble receptors for tumour necrosis factor: a putative marker of disease progression in HIV infection. AIDS 1993; 7: 33-6.

18 Helle M, Boeije L, de Groot E, de Vos A, Aarden L. Sensitive ELISA for interleukin-6. Detection of IL-6 in $\mathrm{O}$ biological fluids: synovial fluids and sera. $\mathcal{f}$ Immunol Methods 1991; 138: 47-56.

19 Hintzen RQ de Jong R, Hack CE, Chamuleau M, de Vries $\frac{D}{O}$ EFR, ten Berge IJM, Borst J, van Lier RAW. A soluble form of the human $T$ cell differentiation antigen CD27 $N$ form of the human T cell differentiation antigen CD27 $\mathrm{N}$
is released after triggering of the TCR/CD3 complex. 7 S Immunol 1991; 147: 29-35.

20 Wendling D, Racadot E, Morel-Fourrier B, Wijdenes J. O Treatment of rheumatoid arthritis with anti-CD4 monoclonal antibody. Open study of 25 patients with the

21 Herzog C, Walker C, Müller W, Rieber P, Reiter C, Rietmüller G, et al. Anti-CD4 antibody treatment of patients with rheumatoid arthritis: I. Effect on clinical $\mathbb{D}$ patients with rheumatoid arthritis: I. Effect on clinical $\stackrel{f}{?}$ 627-42.

22 Choy EH, Kingsley GH, Panayi GS. Treatment with anti- $-\vec{O}$ CD4 monoclonal antibody and acute interstitial nephritis. $\frac{\vec{D}}{2}$ Arthritis Rheum 1993; 36: 723-4.

23 Choy EH, Chikanza IC, Kingsley GH, Corrigall V, Panayi $\stackrel{\odot}{\overparen{D}}$ GS. Treatment of rheumatoid arthritis with single dose 2 or weekly pulses of chimeric anti-CD4 monoclonalo antibody. Scand $¥$ Immunol 1992; 36: 291-8.

24 Morel P, Nicolas JF, Wijdenes J, Revillard JP. Down- $\bigcirc$ regulation of lymphocyte CD4 antigen expression byo Immunol Immunopathol 1992; 64: 248-53.

25 Van der Poll T, van Deventer SJ, Hack CE, Wolbink GJ, Aarden LA, Buller HR, ten Cate JW. Effects on leukocytes after injection of tumor necrosis factor into leukocytes after injection of tumor necro
healthy humans. Blood 1992; 79: 693-8.

26 Van der Lubbe PA, Reiter C, Miltenburg AM, Kruger K, De Ruyter AN, Rieber EP, et al. Treatment of rheumatoid arthritis with a chimeric CD4 monoclonal antibody (cMT412): immunopharmacological aspects and mechanisms of action. Scand ₹ Immunol 1994; 39: 286-94.

27 Raasveld MHM, Bemelman FJ, Schellekens PThA, van Diepen FNJ, van Dongen A, van Royen EA, et al. Complement activation following first dose of OKT3 
induces pulmonary sequestration of granulocytes: an explanation for respiratory side effects. Kidney Int 1993; 43: $1140-9$.

28 Deusch K, Reiter C, Mauthe B, Rietmüller G. Chimeric monoclonal anti-CD4 antibody therapy proves effective for inflammatory bowel disease [abstract]. Gastroenterology 1992; 102: A615.

29 Powrie F, Correa-Oliveira R, Mauze S, Coffman RI. Regulatory interactions between CD45RBhigh and CD45RBlow CD4+ T cells are important for the balance between protective and pathogenic cell-mediated immunity. F Exp Med 1994; 179: 589-600.

30 Wofsy D, Mayes DC, Woodcock J, Seaman WE. Inhibition of humoral immunity in vivo by monoclonal antibody to L3T4: studies with soluble antigens in intact mice. $\mathcal{J}$ Immunol 1985; 135: 1698-701.

31 Gorozny J, Weyand CM, Fathman CG. Long-term humoral unresponsiveness in vivo induced by treatment with monoclonal antibodies against L3T4. F Exp Med 1986; 164: 911-25. 